\title{
Adherence to antihypertensive drugs and its determinants in
}

\author{
an urban setting
}

Accepted: 30/8/2018

Mariwan H. Saka ${ }^{1}$ *

Abstract

Background and objective: Adherence to antihypertensive drugs is very important for controlling blood pressure and preventing its complications. This study aimed to assess the adherence level to antihypertensive drugs in adult hypertensive patients in Erbil city and examine its association with socio-demographic characteristics and access to medications. Methods: A household survey was carried out in 20 quarters of Erbil city using a multi-stage sampling method. Adult patients known to have hypertension were identified. A questionnaire designed for this purpose was used to collect data about the socio-demographic and clinical characteristics, access to antihypertensive drugs, and adherence to drugs.

Results: Of 373 study participants known to have hypertension, $87.9 \%$ were taking their antihypertensive treatment regularly, $5.9 \%$ were taking the treatment irregularly, while $6.2 \%$ were not taking any treatment. Around $77 \%$ of the patients were obtaining their drugs from private pharmacies, and the rest were getting them for free from the public hospitals. A statistically significant association was found between adherence to drugs, and increasing age, duration of having hypertension, and economic status.

Conclusion: The antihypertensive drug adherence among our sample was relatively good. Access to free drugs was limited. Drug adherence was significantly associated with increasing age, increased the duration of hypertension, and economic status. Similar studies need to be conducted in rural areas for comparison purposes.

Keywords: Antihypertensive; Drugs; Adherence; Erbil; Urban Setting.

\section{Introduction}

Hypertension is one of the major public health problems in different parts of the world. ${ }^{1}$ It is one of the leading causes of death and frequent outpatient visits. ${ }^{2}$ In 2010, reports indicated that worldwide 1.2 billion people had hypertension and that the prevalence will increase by $60 \%$ in $2025 .^{3}$ According to a WHO statistics report in 2014, $50 \%$ of the global deaths from coronary heart diseases are due to uncontrolled hypertension. ${ }^{4}$ According to global data analysis, around $80 \%$ of these deaths occur in low and middle-income countries. ${ }^{5}$ It is well known that appropriate treatment of hypertension is required to reduce the risk of cardiovascular disease. This can be attained through a combination of medication and lifestyle intervention. ${ }^{6,7}$ Blood pressure in developing countries is poorly controlled. Based on a systematic review of a number of studies achieved between 2001 and 2007, only 13\% of hypertensive patients had controlled blood pressure. $^{8}$ It is obvious that the key factor in achieving long-term control of blood pressure level is the use of antihypertensive drugs. $^{9}$ Therefore, an important step in controlling hypertension and preventing its complications is adherence to antihypertensive drugs. ${ }^{10}$ In 2001, the WHO adherence meeting defined adherence as "the extent to which a person's behavior taking medication, following a diet, and/or executing lifestyle changes corresponds with agreed

${ }^{1}$ Department of I nternal Medicine, College of Medicine, Hawler Medical University, Erbil, I raq.

* Correspondence: mariwan.haweel@hmu.edu.krd 
recommendations from a health care provider. ${ }^{11}$ Non-adherence could be intentional when the patient decides not to take a treatment due to his/her own belief or it could be unintentional when the patient, for example, simply forget to take medications. ${ }^{12}$ Patients' belief and their health conditions are the main factors contributing to their non-adherence to the treatment regimen. ${ }^{13}$ Factors affecting patients' adherence to antihypertensive therapy could be categorized into two main categories. The first category includes the factors that are related to the patient, such as socio-demographics, knowledge about hypertension, its treatment, and the patient's belief about the treatment. The second category includes the factors related to the provision of antihypertensive medications, such as the relationship between hypertensive patients and healthcare providers. Other relevant factors include the number of pills, side effects, and comorbidities. ${ }^{14}$ The degree of nonadherence to antihypertensive treatment is assumed to be higher in developing countries compared to developed countries. This can be attributed to the health resources shortage and healthcare access difficulties. ${ }^{15}$ Studies carried out in Cameron in 2014, ${ }^{16}$ Nigeria in $2010^{17}$ and Pakistan in $2008,{ }^{18}$ showed an adherence rate to antihypertensive drugs of $33.3 \%$, $32.1 \%$, and $48.3 \%$, respectively. A study conducted in Turkey in 2017 revealed a relatively higher adherence rate $(78.2 \%)$ to the pharmacological treatment of hypertensive patients. ${ }^{19}$ In a study conducted in Garmian province of the Iraqi Kurdistan in 2014, the levels of drug adherence among hypertensive and diabetic patients were $29.8 \%$ for high-level adherence compared to $50.6 \%$ and $19.6 \%$ for moderate and lower adherence levels respectively. ${ }^{20}$ Adherence to antihypertensive drugs is very crucial in controlling blood pressure and preventing its complications, but studies addressing this important topic are rare in Erbil. Therefore, this study aimed to assess the level of adherence to antihypertensive drugs among the Erbil patients, and examine the association between patient's adherence to antihypertensive drugs and a range of factors like socio-demographic characteristics and access to drugs.

\section{Methods}

The study was conducted in Erbil city, Iraq, from April to June 2017. This study reports part of the data collected from a wider household survey to assess hypertension in the adult population in Erbil city. A multi-stage sampling method was used to collect the study subjects. In the first stage, Erbil city was divided into 20 quarters based on the administrative map of the city. Later on, a systematic random sampling method was used to collect 30 households per each quarter. The first household in each quarter was selected randomly, and the next households were selected by systematic random sampling. The study population included all the adult inhabitants of these households, aged 18 years and more. Data collection was done through direct interviews using a special questionnaire designed for this purpose. The questionnaire included personal and socio-demographic information such as age, gender, marital status, educational level, occupation, smoking status, alcohol consumption, dietary habits, physical activities, family history of having hypertension, and questions on adherence to antihypertensive drugs, duration of hypertension, access to drugs, and types of antihypertensive drugs. The blood pressure was measured in the sitting position using calibrated mercury instruments. Systolic and diastolic blood pressure was measured for each participant on two occasions; the first reading after at least five minutes rest, and the second one after five minutes of the first reading. We used the 2017 American College of Cardiology/American Heart Association new guidelines for the prevention, detection, evaluation, and management of high blood pressure in 
adults that set a cut point of $130 / 80 \mathrm{~mm} \mathrm{Hg}$ for hypertension. ${ }^{21}$ Ethical approval was obtained from the Research Ethics Committee at the College of Medicine, Hawler Medical University. Informed consent was obtained from the participants who were assured about the anonymity of the study. The participants were informed about their blood pressure status, and those with elevated blood pressure, especially the newly diagnosed hypertensive were advised about seeking appropriate health care for that. This study reports the data obtained from the known hypertensive cases among the total sample. The statistical package for the social sciences (version 19) was used for data entry and analysis. Chi-square test was used for comparing proportions. A $P$ value equal to or less than 0.05 was considered statistically significant.

\section{Results}

Of 373 study participants who were already diagnosed as having hypertension, $56.8 \%$ were 60 years old and older, 23.9\% 50-59 years old, and $19.3 \% 20-49$ years old. The mean $\pm S D$ age of the participants was $46.36 \pm 16.27$, with a minimum age of 20 and a maximum of 92 years. Females comprised $81.8 \%$ of the participants, $88.7 \%$ were unemployed, and $98.9 \%$ were married. With regard to their educational level, $68.9 \%$ were illiterate, $16.1 \%$ had primary education level and $3.8 \%$, and $11.3 \%$ for secondary and tertiary levels, respectively. Most of the participants $(92.2 \%)$ assessed themselves as having a medium socioeconomic level, as shown in Table 1. With regard to patients' adherence to taking antihypertensive drugs, $87.9 \%$ were taking their antihypertensive treatment regularly, 5.9\% were taking the treatment irregularly, while $6.2 \%$ were not taking any treatment. Around $77 \%$ of these hypertensive patients get their antihypertensive treatment from private pharmacies, and only around $12.6 \%$ of them get the treatment free of charge from the public hospitals. Regarding the category of antihypertensive drugs the patients receive, most of them (42.4\%) receive angiotensin receptor blockers, $16.6 \%$ calcium channel blockers, $11.3 \%$ beta blockers, $4 \%$ angiotensin-converting enzyme inhibitors, $3.5 \%$ diuretic drugs, and the rest were receiving a combination of two or three of the above-mentioned categories. Around one-quarter of the participants were diagnosed with hypertension for 11 and more years, compared to $28.2 \%$ for $6-10$ years and $46.9 \%$ for five years and less. Only $46.6 \%$ had a positive family history in the family, and $34.4 \%$ had controlled blood pressure on examination. Only $7.5 \%$ of the participants had normal weight compared to $26.5 \%$ and $66 \%$ of overweight and obese nutritional status, respectively. Around 95\% were nonsmokers, 99.5\% nonalcoholics, $98.1 \%$ don't add table salt to their food, $87.2 \%$ had an active lifestyle, and $97.1 \%$ didn't perform any form of exercises as shown in Table 2. There was a statistically significant association between compliance with antihypertensive drugs and increasing age, increasing the duration of having hypertension and economic status. A nonsignificant association was found with gender, educational level, access to drugs, or the source of obtaining antihypertensive drugs and the family history of hypertension, as shown in Table 3. 
Adherence to antihypertensive drugs and .......

Zanco J. Med. Sci., Vol. 23, No. (3), December, 2019

https:/ / doi.org/ 10.15218/ zjms.2019.037

Table 1: The socio-demographic characteristics of the studied sample.

\begin{tabular}{|c|c|c|}
\hline Variable & Frequency & Percentage \\
\hline \multicolumn{3}{|l|}{ Age } \\
\hline $20-29$ & 4 & $(1.1)$ \\
\hline $30-39$ & 16 & $(4.3)$ \\
\hline $40-49$ & 52 & (13.9) \\
\hline $50-59$ & 89 & $(23.9)$ \\
\hline$\geq 60$ & 212 & $(56.8)$ \\
\hline \multicolumn{3}{|l|}{ Gender } \\
\hline Male & 68 & $(18.2)$ \\
\hline Female & 305 & $(81.8)$ \\
\hline \multicolumn{3}{|l|}{ Employment } \\
\hline No & 331 & $(88.7)$ \\
\hline Yes & 42 & $(11.3)$ \\
\hline \multicolumn{3}{|l|}{ Education } \\
\hline Illiterate & 257 & (68.9) \\
\hline Primary & 60 & (16.1) \\
\hline Secondary & 14 & (3.8) \\
\hline Tertiary & 42 & $(11.3)$ \\
\hline \multicolumn{3}{|l|}{ Marital status } \\
\hline Single & 4 & (1.1) \\
\hline Married & 369 & $(98.9)$ \\
\hline \multicolumn{3}{|l|}{ Religion } \\
\hline Muslim & 360 & $(96.5)$ \\
\hline Christian & 13 & (3.5) \\
\hline \multicolumn{3}{|l|}{ Ethnicity } \\
\hline Kurd & 354 & $(94.9)$ \\
\hline Arab & 3 & $(0.8)$ \\
\hline Turkman & 3 & $(0.8)$ \\
\hline Chaldean/Assyrian & 13 & (3.5) \\
\hline \multicolumn{3}{|c|}{ Socioeconomic status (self assessment) } \\
\hline Poor & 24 & $(6.4)$ \\
\hline Medium & 344 & $(92.2)$ \\
\hline Well & 5 & $(1.3)$ \\
\hline \multicolumn{3}{|l|}{ Accommodation } \\
\hline Own house & 355 & $(95.2)$ \\
\hline Rented & 18 & $(4.8)$ \\
\hline Total & 373 & $(100)$ \\
\hline
\end{tabular}


Table 2: Clinical characteristics of the study participants.

\begin{tabular}{|c|c|c|}
\hline Characteristic & Frequency & Percent \\
\hline \multicolumn{3}{|l|}{ Compliance with antihypertensive treatment } \\
\hline Regularly take treatment & 328 & $(87.9)$ \\
\hline Irregularly take treatment & 22 & $(5.9)$ \\
\hline Do not take treatment & 23 & $(6.2)$ \\
\hline \multicolumn{3}{|l|}{ Access to antihypertensive drugs } \\
\hline Public hospital & 47 & $(12.6)$ \\
\hline Private pharmacy & 288 & $(77.2)$ \\
\hline Missing data & 38 & $(10.2)$ \\
\hline \multicolumn{3}{|l|}{ Antihypertensive drug class } \\
\hline Angiotensin receptor blocker & 158 & $(42.4)$ \\
\hline Angiotensin converting enzyme inhibitors & 15 & $(4.0)$ \\
\hline Calcium channel blockers & 62 & $(16.6)$ \\
\hline Diuretic & 13 & $(3.5)$ \\
\hline Beta blockers & 42 & $(11.3)$ \\
\hline Angiotensin receptor blocker + calcium channel blockers & 15 & $(4.0)$ \\
\hline Angiotensin receptor blocker + beta blockers & 3 & $(0.8)$ \\
\hline Angiotensin receptor blocker + diuretic & 23 & $(6.2)$ \\
\hline Angiotensin converting enzyme inhibitors + calcium channel blockers & 2 & $(0.5)$ \\
\hline Angiotensin converting enzyme inhibitors + diuretic & 23 & $(6.2)$ \\
\hline Angiotensin converting enzyme inhibitors + beta blockers & 2 & $(0.5)$ \\
\hline Diuretic + beta blockers & 1 & $(0.3)$ \\
\hline Angiotensin receptor blocker+ calcium channel blockers + diuretic & 6 & $(1.6)$ \\
\hline Missing data & 30 & $(8.0)$ \\
\hline \multicolumn{3}{|l|}{ Duration of hypertension } \\
\hline$\leq 5$ years & 175 & $(46.9)$ \\
\hline $6-10$ years & 105 & $(28.2)$ \\
\hline$\geq 11$ years & 93 & $(24.9)$ \\
\hline \multicolumn{3}{|l|}{ Family history of hypertension } \\
\hline No & 199 & $(53.4)$ \\
\hline Yes & 174 & $(46.6)$ \\
\hline \multicolumn{3}{|l|}{ Blood pressure on examination } \\
\hline Controlled & 129 & $(34.6)$ \\
\hline Uncontrolled & 244 & $(65.4)$ \\
\hline \multicolumn{3}{|l|}{ Weight status } \\
\hline Normal weight & 28 & $(7.5)$ \\
\hline Overweight & 99 & $(26.5)$ \\
\hline Obese & 246 & $(66.0)$ \\
\hline \multicolumn{3}{|l|}{ Smoking } \\
\hline No & 355 & $(95.2)$ \\
\hline Yes & 18 & $(4.8)$ \\
\hline \multicolumn{3}{|l|}{ Alcohol consumption } \\
\hline No & 371 & $(99.5)$ \\
\hline Yes & 2 & $(0.5)$ \\
\hline \multicolumn{3}{|l|}{ Table salt intake } \\
\hline No & 366 & $(98.1)$ \\
\hline Yes & 7 & $(1.9)$ \\
\hline \multicolumn{3}{|l|}{ Lifestyle } \\
\hline Sedentary & 48 & $(12.9)$ \\
\hline Active & 325 & $(87.2)$ \\
\hline \multicolumn{3}{|l|}{ Performing exercise } \\
\hline No & 362 & $(97.1)$ \\
\hline Yes & 11 & $(2.9)$ \\
\hline Total & 373 & $(100)$ \\
\hline
\end{tabular}


Table 3: Association between patients' adherence to treatment and other variables.

\begin{tabular}{|c|c|c|c|c|}
\hline \multirow{3}{*}{ Variables } & \multicolumn{3}{|c|}{ Compliance } & \multirow{3}{*}{$P$ value } \\
\hline & Yes & No & Total & \\
\hline & No. (\%) & No. (\%) & No. (\%) & \\
\hline \multicolumn{5}{|l|}{ Age groups } \\
\hline$<60$ years & $135(83.9)$ & $26(16.1)$ & $161(100)$ & 0.035 \\
\hline$\geq 60$ years & $193(91.0)$ & $19(9.0)$ & $212(100)$ & \\
\hline \multicolumn{5}{|l|}{ Gender } \\
\hline Male & $60(88.2)$ & $8(11.8)$ & $68(100)$ & 0.933 \\
\hline Female & $268(87.9)$ & $37(12.1)$ & $305(100)$ & \\
\hline \multicolumn{5}{|l|}{ Education level } \\
\hline Illiterate & $225(87.5)$ & $32(12.5)$ & $257(100)$ & 0.947 \\
\hline Primary & $53(88.3)$ & $7(11.7)$ & $60(100)$ & \\
\hline Secondary & $13(92.9)$ & $1(7.1)$ & $14(100)$ & \\
\hline Tertiary & $37(88.1)$ & $5(11.9)$ & $42(100)$ & \\
\hline \multicolumn{5}{|l|}{ Economic status } \\
\hline Poor & $16(66.7)$ & $8(33.3)$ & $24(100)$ & 0.004 \\
\hline Medium/Well & $312(89.4)$ & $37(10.6)$ & $349(100)$ & \\
\hline \multicolumn{5}{|l|}{ Access to drugs } \\
\hline Public hospitals & $43(91.5)$ & $4(8.5)$ & $47(100)$ & 0.428 \\
\hline Private pharmacies & $272(94.4)$ & $16(5.6)$ & $288(100)$ & \\
\hline \multicolumn{5}{|c|}{ Family history of hypertension } \\
\hline No & $177(88.9)$ & $22(11.1)$ & $199(100)$ & 0.522 \\
\hline Yes & $151(86.8)$ & $23(13.2)$ & $174(100)$ & \\
\hline \multicolumn{5}{|c|}{ Duration of hypertension } \\
\hline$\leq 5$ years & $142(81.1)$ & $33(18.9)$ & $175(100)$ & $<0.001$ \\
\hline $6-10$ years & $95(90.5)$ & $10(9.5)$ & $105(100)$ & \\
\hline$\geq 11$ years & $91(97.8)$ & $2(2.2)$ & $93(100)$ & \\
\hline
\end{tabular}




\section{Discussion}

Hypertension or high blood pressure is a well-known risk factor among other important factors for cardiovascular diseases. Worldwide, it is also considered to be the leading cause of premature adult deaths. ${ }^{4}$ Studies showed that deaths' number due to hypertension increased from 7.6 to 9.4 million from the year 2000 to $2013 .^{22}$ Poor adherence to hypertensive medications is an important barrier among other barriers in front of achieving an appropriate blood pressure control. ${ }^{23} \mathrm{We}$ undertook this study to assess the hypertensive patients' adherence to the prescribed antihypertensive drugs in Erbil city and explore factors that may affect this adherence. This study showed that $87.9 \%$ of the studied sample were adherent to their treatment compared to only $12.1 \%$ of the hypertensive patients who were either not or incompletely adherent to their antihypertensive treatment. The low non-adherence rate might be attributed to the fact that the study was conducted in the city and did not include other rural or semi-rural areas where it is expected to have higher non-adherence rates. Around $77 \%$ of the patients enrolled in this study stated that their main access to antihypertensive drugs was from private pharmacies rather than public hospitals. This may also explain to some extent the low non-adherence rate since patients do not wait to get drugs from public hospitals or through other governmental health care delivery institutions. These results were somehow close to those of a study conducted in Turkey, which showed a rate of $78.2 \%$ adherence of patients to antihypertensive drugs, ${ }^{19}$ but a study conducted in Shiraz, Iran revealed a much lower $(39.6 \%)$ adherent rate compared to our study. ${ }^{24}$ Our results were also much higher than those of a study conducted in Saudi Arabia in which only $27.9 \%$ of the patients were classified as a perfect adherent to antihypertensive drugs. ${ }^{25}$ A significant statistical association was found in this study, between adherence to treatment and participants' age. Those whose age was equal or more than 60 years had a $91 \%$ adherence rate compared to $83.9 \%$ rate for those whose age is less than 60 years. This might be because older adults are more concerned about their health status to decrease the probability of complications that may arise from hypertension control failure. These results were consistent with those of a study conducted in the general teaching hospitals in Erbil, which revealed compliance is significantly higher among old age (> 65 years) patients. ${ }^{26}$ Although insignificant, other studies conducted in the Ardabil city in Iran, ${ }^{27}$ Turkey, ${ }^{28}$ Saudi Arabia, ${ }^{25}$ Cameron, ${ }^{29}$ and Finland ${ }^{30}$ also showed a higher rate of adherence to antihypertensive drugs among older patients. Gender wise, although statistically insignificant, our results showed a slightly higher adherence rate among males $(88.2 \%)$ compared to females $(87.9 \%)$. Generally, females are more mindful than males in following physician's instructions, particularly in relation to medications taking. Similar insignificant association results were also reported in a number of studies like those in Iran, ${ }^{27}$ Saudi Arabia, ${ }^{25}$ Cameron, ${ }^{29}$ and Finland. ${ }^{30}$ A significant association was reported in a study conducted in Turkey with a higher rate of adherence among females compared to males. ${ }^{28}$ Unlikely, in a study conducted in Erbil in 2015, males had a significantly higher $(63.7 \%)$ compliance rate compared to females $(38.3 \%) .{ }^{26} \mathrm{~A}$ higher insignificant adherence level was reported among those with secondary education level (92.9\%), compared to illiterates $(87.5 \%)$, primary $(88.3 \%)$, and tertiary $(88.1 \%)$ education levels. Ideally, those with higher educational levels should have a higher adherence rate, but because most $(68.9 \%)$ of the participants were illiterate, the results did not come as expected. The study results were consistent with those of Cameron $^{29}$ and Finland ${ }^{30}$ studies, which showed an insignificant association between drug compliance and education 
level. However, our results were inconsistent with those of the Saudi Arabia study, which revealed a significantly higher rate of perfect adherence to antihypertensive drugs among patients with formal education (40.4\%) compared to nonformal education (25.7\%). ${ }^{25}$ Unexpectedly, the study conducted in Erbil in 2015, revealed a significantly higher rate of compliance among illiterate patients (70\%) compared to those who only read and write $(64 \%)$, primary $(9.8 \%)$ and secondary $(36 \%)$ education levels. ${ }^{26}$ With regard to the economic situation of the patients, a significantly higher adherence level was found among those with medium and higher economic situations (89.4\%) compared to the poor patients $(66.7 \%)$. Non significant results were reported in the study conducted in Saudi Arabia ${ }^{25}$ which showed an insignificant association of compliance with antihypertensive treatment among low income and high-income patients, and that conducted in Cameron which showed an insignificant association of treatment compliance among employed and unemployed patients. ${ }^{29}$ The duration of having or being diagnosed as having hypertension was also tested, and the study revealed a significantly higher compliance rate $(97.8 \%)$ among those who are diagnosed as having hypertensive for eleven and more years, compared to 6-10 years $(90.5 \%)$ and five or fewer years $(81.1 \%)$. Unlikely, the study conducted in Erbil in 2015 revealed a higher significant compliance rate $(65.8 \%)$ among those having hypertension for ten or fewer years compared to more than ten years $(42 \%){ }^{26}$ A non-significant association was reported between compliance and the duration of having hypertension in the study conducted in Finland. ${ }^{30}$ This study is limited by the low male representation and lack of adequate and reliable data regarding comorbidities. For the assessment of adherence, we depended on interviewing the patients using a questionnaire. More accurate data can be obtained by using other methods of assessing adherence like pill count, electronic monitoring, or therapeutic drug monitoring. There are many other important factors that can affect the adherence to antihypertensive drugs and be not assessed by this study. Examples of these factors include the cost of medication, the frequency of daily medication, the presence of comorbidities, and the simultaneous admission of other drugs.

\section{Conclusion}

The antihypertensive drug adherence among our sample was relatively good and higher compared to other studies conducted in a number of our neighboring countries. Access to drugs from public facilities was limited. Adherence to medications was significantly associated with the increasing age, increased the duration of being hypertensive and the economic status. Doctors should always assess and improve adherence by adapting the drug regimen that is simple, easy to follow, and fits the patient's lifestyle. More comprehensive future studies are required to assess the other factors that could be associated with adherence that were not covered by this study and to find and assess methods of improving adherence.

\section{Competing interests}

The author declares no competing interests.

\section{References}

1. Kaur P, Rao SR, Radhakrishnan E, Rajasekar D, Gupte MD. Prevalence, awareness, treatment, control and risk factors for hypertension in a rural population in South India. Int $\mathrm{J}$ Public Health 2012; 57(1):87-94.

2. Perkovic V, Huxley R, Wu Y, Prabhakaran D, MacMahon $S$. The burden of blood pressurerelated disease: A neglected priority for global health. Hypertension 2007; 50:991-7.

3. Kearney PM, Whelton M, Reynolds K, Muntner P, Whelton PK, He J. Global burden of hypertension: analysis of worldwide data. Lancet 2005; 365(9455):217-23.

4. WHO. World Health Statistics 2014 Report Geneva: WHO; 2014. (Accessed January 12, 2018, at http://apps.who.int/iris/bitstream/10665/ 112738/1/9789240692671_eng.pdf ). 
5. WHO. World Health Statistics 2011. Geneva: WHO; 2011.

6. WHO. Prevention of Cardiovascular Disease. Pocket Guidelines for assessment and management of cardiovascular risk. WHO Press; 2007.

7. Mancia G, Fagard R, Narkiewicz K, Redon J, Zanchetti A, Böhm M, et al. ESH/ESC Guidelines for the Management of Arterial Hypertension. Blood Press 2013; 22(4):193-278.

8. Pereira $\mathrm{M}$, Lunet $\mathrm{N}$, Azevedo A, Barros $\mathrm{H}$. Differences in prevalence, awareness, treatment and control of hypertension between developing and developed countries. J Hypertens 2009; 27:963-75.

9. Dragomir A, Côté R, Roy L, Blais L, Lalonde L, Bérard $A$, et al. Impact of adherence to antihypertensive agents on clinical outcomes and hospitalization costs. Medical Care 2010; 48(5):418-25.

10. Magadza C, Radloff S E, Srinivas SC. The effect of an educational intervention on patients' knowledge about hypertension, beliefs about medicines, and adherence. Res Social Admi Pharm 2009; 5(4):363-75.

11. De Geest S, Sabate' E. Adherence to long-term therapies: evidence for action. Eur $\mathrm{J}$ Cardiovasc Nurs J Work Group Cardiovasc Nurs Eur Soc Cardiol 2003; 2(4):323.

12. Hashmi SK, Afridi MB, Abbas K, Sajwani RA, Saleheen D, Frossard PM, et al. Factors associated with adherence to anti-hypertensive treatment in Pakistan. PLoS One 2007; 2:e280.

13. Hsiao CY, Chang C, Chen CD. An investigation on illness perception and adherence among hypertensive patients. Kaohsiung $\mathrm{J}$ Med Sci 2012; 28:442-7.

14. Van der Feltz-Cornelis CM, Van Oppen P, Van Marwijk HW J, De Beurs E, Van Dyck R. A patient-doctor relationship questionnaire (PDRQ-9) in primary care: development and psychometric evaluation. Gen Hosp Psychiatry 2004; 26(2):115-20.

15. WHO. Adherence to Long-Term Therapies: Evidence for Action. Geneva: WHO; 2003.

16. Adidja NM. Adherence to anti-hypertensive treatment in the Buea Health District a community based study. MD thesis. Buea: University of Buea; 2014.

17. Busari OA, Olanrewaju TO, Desalu OO, Opadijo OG, Jimoh AK, Agboola SM, et al. Impact of patients' knowledge, attitude and practices on hypertension on compliance with antihypertensive drugs in a resource-poor setting. TAF Prev Med Bull 2010; 9(2):87-92.

18. Ahmed N, Abdul Khaliq M, Shah SH, Anwar W. Compliance to antihypertensive drugs, salt restriction, exercise and control of systemic hypertension in hypertensive patients at Abbottabad. J Ayub Med Coll Abbottabad 2008; 20(2):66-9.
19. Selcuk KT, Cevik C, Mercan Y, Koca H. Hypertensive patients' adherence to pharmacological and non-pharmacological treatment methods, in Turkey. IJCMPH 2017; 4(8):2648-57.

20. Shakor JK, Qader SS. Drug adherence among diabetic and hypertensive patients in association with demographic and healthy behavior. IJSR 2014; 3(12):1998-2003.

21. Whelton PK, Carey RM, Aronow WS, Casey DE, Collins KJ, Himmelfarb CD, et al. 2017 ACC/ AHA/AAPA/ABC/ACPM/AGS/APhA/ASH/ASPC/ NMA/PCNA guideline for the prevention, detection, evaluation, and management of high blood pressure in adults: a report of the American College of Cardiology/American Heart Association Task Force on Clinical Practice Guidelines. JACC 2018; 71(19):e127-248.

22. Lim SS, Vos T, Flaxman AD, Danaei G, Shibuya $\mathrm{K}$, Adair-Rohani $\mathrm{H}$, et al. A comparative risk assessment of burden of disease and injury attributable to 67 risk factors and risk factor clusters in 21 regions, 1990-2010: A systematic analysis for the global burden of disease study 2010. Lancet 2012; 380:2224-60.

23. Waeber B, Burnier M, Brunner $H$. How to improve adherence with prescribed treatment in hypertensive patients? J Cardiovasc Pharmacol 2000; 35:23-6.

24. Hadi N, Rostami-Gooran N. Determinant factors of medical compliance in hypertensive patients of Shiraz, Iran. Arch Iranian Med 2004; 7(4):292-6.

25. Alsolami F, Correa-Velez I, Hou X. Factors affecting antihypertensive medications adherence among hypertensive patients in Saudi Arabia. AJMMS 2015; 5(4):1-9.

26. Ismael DH, Qadir CS. Factor affecting treatment compliance of hypertensive patients in Erbil city. KJNS 2015; 5(2):1-8.

27. Kamran A, Ahari SS, Biria M, Malepour A, Heydari H. Determinants of patient's adherence to hypertension medications: Application of health belief model among rural patients. Ann Med Health Sci Res 2014; 4(6):9-7.

28. Mollaoglu M, Solmaz G, Mollaoglu M. Adherence to therapy and quality of life in hypertensive patients. Acta Clin Croat 2015; 54:438--44.

29. Akoko BM, Fon PN, Ngu RC, Ngu KB. Knowledge of hypertension and compliance with therapy among hypertensive patients in the Bamenda health district of Cameron: A cross-sectional study. Cardiol Ther 2017; 6:5367.

30. Jokisalo E, Kumpusalo E, Enlund H, Halonen P, Takala J. Factors related to non-compliance with antihypertensive drug therapy. J Hum Hypertens 2002; 16:5-83. 